\title{
The Sub-Polar Gyre Index - a community data set for application in fisheries and environment research
}

\author{
Barbara Berx ${ }^{1}$ and Mark R. Payne ${ }^{2}$ \\ ${ }^{1}$ Marine Scotland Science, 375 Victoria Road, Aberdeen, AB11 9DB, UK \\ ${ }^{2}$ Centre for Ocean Life, Technical University of Denmark, National Institute of Aquatic Resources, \\ 2920 Charlottenlund, Denmark \\ Correspondence to: Barbara Berx (b.berx@marlab.ac.uk)
}

Received: 22 October 2016 - Discussion started: 1 November 2016

Revised: 14 March 2017 - Accepted: 15 March 2017 - Published: 18 April 2017

\begin{abstract}
Scientific interest in the sub-polar gyre of the North Atlantic Ocean has increased in recent years. The sub-polar gyre has contracted and weakened, and changes in circulation pathways have been linked to changes in marine ecosystem productivity. To aid fisheries and environmental scientists, we present here a time series of the Sub-Polar Gyre Index (SPG-I) based on monthly mean maps of sea surface height. The established definition of the SPG-I is applied, and the first EOF (empirical orthogonal function) and PC (principal component) are presented. Sensitivity to the spatial domain and time series length are explored but found not to be important factors in terms of the SPG-I's interpretation. Our time series compares well with indices presented previously. The SPG-I time series is freely available online (http://dx.doi.org/10.7489/1806-1), and we invite the community to access, apply, and publish studies using this index time series.
\end{abstract}

\section{Introduction}

The sub-tropical and sub-polar gyres are the dominant features of the surface circulation of the North Atlantic Ocean (Fig. 1). Both are driven by the combination of permanent wind features, heat-input variation with latitude, and the global overturning circulation. The sub-tropical gyre is formed by the synthesis of the Gulf Stream, North Atlantic Current, Canary Current, and North Equatorial Current to yield a nearly continuous, anticyclonic circulation in the sub-tropical North Atlantic Ocean. Its equivalent in the subpolar region can be considered as a cyclonic gyre encompassing the North Atlantic, East Greenland, and Labrador Currents (Fig. 1). Within the North Atlantic, changes in the strength and extent of the sub-polar gyre have been linked to changes in the advection of water masses (Häkkinen and Rhines, 2009) and changes in their properties (Holliday et al., 2008; Johnson et al., 2013). These changes in the strength and extent of the sub-polar gyre have been attributed to the strong overturning circulation observed in the preceding years (Häkkinen and Rhines, 2004; Bersch et al., 2007). More recently, marine ecologists have reported changes in the ecosystem associated with changes in circulation in the North Atlantic and particularly the sub-polar gyre region (e.g. Hátún et al., 2009a, b; Payne et al., 2012).

Based on a survey of research scientists within the International Council on the Exploitation of the Seas (ICES) community, the Working Group on Operational Oceanographic products for Fisheries and Environment (WGOOFE; Berx et al., 2011) identified a need from fisheries and environmental scientists for freely accessible oceanographic data, in a suitable data format and with operational delivery. Within the climate community, the need for large volumes of data to be distilled into readily accessible, user-friendly data sets has recently driven the development of the Climate Data Guide (Schneider et al., 2013; Overpeck et al., 2011). This site provides a community-based overview of available data products and includes some expert guidance on the strengths and weaknesses of the products as well as information on their derivation. In its work as an interface between the ICES community and the operational oceanography community, WGOOFE found that index-based products - where a complex spatio-temporal data set, process, or state estimate may 


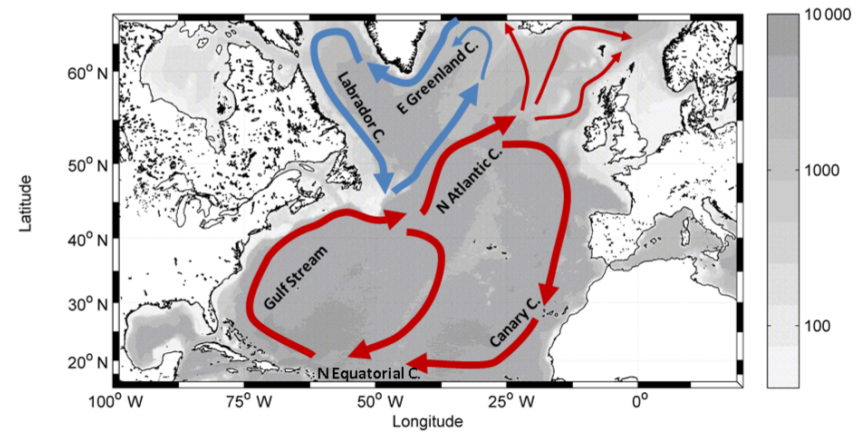

Figure 1. Map of the sub-tropical and sub-polar North Atlantic with a schematic representation of the ocean circulation.

be reduced to a single time series, such as the North Atlantic Oscillation Index (NAO; Hurrell and NCAR Staff, 2013) remain a major gap in the available oceanographic data products (ICES, 2012a). Recently, Bessières et al. (2013) presented three index-based oceanographic data products developed by the MyOcean project: the El Niño indicator, the Kuroshio Extension indicator, and the Ionian Surface Circulation indicator. However, these index time series have not yet been made readily available to the wider community. To date, no readily accessible up-to-date data set exists summarizing the sub-polar gyre's dynamics. This limits some researchers in the field of ecosystem science in the search for drivers of ecosystem variability within the region and therefore also the development of improved fisheries management tools.

The sub-polar gyre index has been applied recently in a number of studies investigating ecosystem variability. Johnson et al. (2013) present a decline in nutrient concentrations (particularly nitrate and phosphate concentrations) in the Rockall Trough related to the strength of the sub-polar gyre. Recent work has even highlighted potential linkages between sub-polar gyre dynamics and higher trophic levels, including commercially important fish stocks (Hátún et al., 2009a, b, 2016). In 2012, the ICES Working Group on Widely Distributed Stocks (WGWIDE) emphasized the absence of such a data product as a key obstacle when studying distribution and abundance changes in economically important fish stocks, such as mackerel and blue whiting (ICES, 2012b).

The data set presented here aims to fill this gap in indexbased operational oceanographic data products by presenting a time series of the Sub-Polar Gyre Index (SPG-I) extending from the start of satellite altimetry records (January 1993) to the present. The data set presented is freely available and easily citable. In Sect. 2, we outline the underlying data set and methodology for our SPG-I calculation; in Sect. 3 we present the data product and its sensitivities and compare our time series with other published results of SPG-I variability; and finally we present how to access the SPG-I data product and acknowledge its use (Sect. 4), followed by a brief conclusion and outlook (Sect. 5).

\section{Methodology}

\subsection{Sea surface height data}

The altimeter products used to create the SPG-I were obtained through the Copernicus Marine Environment Monitoring Service (CMEMS; product identifier: SEALEVEL_GLO_SLA_MAP_L4_REP_OBSERVATIONS _008_027). For our analysis, we obtained the delayed time, global, daily Maps of Sea Level Anomaly (MSLAs) on a $1 / 4^{\circ}$ by $1 / 4^{\circ}$ grid. The product is the result of merging all available satellite missions at a given time, resulting in a better-quality product (particularly in recent years). Monthly mean maps were created by averaging the multimission daily maps by month, while seasonal climatology maps were calculated by averaging the monthly mean maps within the same month for all complete years (1993-2015). The climatological maps therefore represent the average conditions for each month of the year throughout the observation period. To avoid issues with observations in grid points on land, a land-sea mask was obtained by interpolating the $1 / 12^{\circ}$ by $1 / 12^{\circ}$ TerrainBase database (National Geophysical Data Center, 1995) on to the same grid as the altimeter data. The land-sea mask was also used to remove altimeter data in the Pacific Ocean, Great Lakes, and Mediterranean Sea. The altimeter data set starts in January 1993, and the latest update obtained from CMEMS extends to April 2016.

\subsection{Calculation of SPG-I}

We followed the method of Häkkinen and Rhines (2004) to calculate the SPG-I, which has been defined as the first principal component (PC1) of an empirical orthogonal function analysis (EOFA) of the sea level anomaly field in the North Atlantic. In Sect. 3, our results are compared to similarly defined gyre indices based on altimeter data, although alternative indices based on sea surface temperature and wind stress curl have also been defined by Hátún et al. (2009a) and Häkkinen et al. (2011), respectively.

In our analysis, we restricted the geographical extent to a rectangular area focused on the North Atlantic's sub-polar gyre (delimited by the $60^{\circ} \mathrm{W}$ and $10^{\circ} \mathrm{E}$ meridians and the 40 and $65^{\circ} \mathrm{N}$ parallels). The exact choice of spatial domain varies between authors - here we have chosen a region focused on the sub-polar gyre region itself. However, we also perform sensitivity analyses to examine the effect of this choice on the resulting index time series. Seasonality in the monthly mean observations of sea level anomaly was removed by subtracting the relevant climatological sea level anomaly map. We calculated the monthly SPG-I based on these deseasonalized maps of sea level anomaly. A yearly SPG-I is calculated based on the average of the deseasonal- 
Table 1. Overview of defined regions to investigate sensitivity of SPG-I to the chosen spatial coverage (regions are also shown in Fig. 3). The abbreviations in the first column correspond to those used in figure legends. S: S. Häkkinen time series; B: time series presented here; R: time series based on different regions; 1X1: time series presented here based on a $1^{\circ}$ by $1^{\circ}$ grid; $2 \mathrm{X} 2$ : time series presented here based on a $2^{\circ}$ by $2^{\circ}$ grid; all other time series presented here are based on a $1 / 4^{\circ}$ by $1 / 4^{\circ}$ grid.

\begin{tabular}{lrr|rr}
\hline Region & \multicolumn{2}{c|}{ Longitude } & \multicolumn{2}{c}{ Latitude } \\
& Left & Right & Bottom & Top \\
\hline S & $100^{\circ} \mathrm{W}$ & $20^{\circ} \mathrm{E}$ & $15^{\circ} \mathrm{N}$ & $65^{\circ} \mathrm{N}$ \\
$\mathrm{B}, 1 \mathrm{X} 1,2 \mathrm{X} 2$ & $60^{\circ} \mathrm{W}$ & $10^{\circ} \mathrm{E}$ & $40^{\circ} \mathrm{N}$ & $65^{\circ} \mathrm{N}$ \\
R1 & $100^{\circ} \mathrm{W}$ & $30^{\circ} \mathrm{E}$ & $0^{\circ} \mathrm{N}$ & $66^{\circ} \mathrm{N}$ \\
R2 & $95^{\circ} \mathrm{W}$ & $25^{\circ} \mathrm{E}$ & $5^{\circ} \mathrm{N}$ & $66^{\circ} \mathrm{N}$ \\
R3 & $90^{\circ} \mathrm{W}$ & $20^{\circ} \mathrm{E}$ & $10^{\circ} \mathrm{N}$ & $66^{\circ} \mathrm{N}$ \\
R4 & $85^{\circ} \mathrm{W}$ & $15^{\circ} \mathrm{E}$ & $15^{\circ} \mathrm{N}$ & $60^{\circ} \mathrm{N}$ \\
R5 & $80^{\circ} \mathrm{W}$ & $10^{\circ} \mathrm{E}$ & $15^{\circ} \mathrm{N}$ & $60^{\circ} \mathrm{N}$ \\
R6 & $75^{\circ} \mathrm{W}$ & $5^{\circ} \mathrm{E}$ & $30^{\circ} \mathrm{N}$ & $66^{\circ} \mathrm{N}$ \\
R7 & $65^{\circ} \mathrm{W}$ & $0^{\circ} \mathrm{E}$ & $45^{\circ} \mathrm{N}$ & $66^{\circ} \mathrm{N}$ \\
R8 & $60^{\circ} \mathrm{W}$ & $5^{\circ} \mathrm{W}$ & $45^{\circ} \mathrm{N}$ & $66^{\circ} \mathrm{N}$ \\
\hline
\end{tabular}

ized sea level anomalies by calendar year, with only complete years included in the analysis.

EOFA is a well-established analysis technique, but for completeness a short description follows. For more in-depth information, we refer the reader to Emery and Thomson (2001).

A major strength of EOFA is the reduction in data volume: a large data set can be reduced to a smaller one containing the most significant fraction of variability contained in the original data. In particular, it can often reduce large spatial data sets to a more manageable size. We can consider the altimeter data set as a time series of $I$ time instances at $J$ spatial locations, defined by the point's latitude and longitude on the grid. During EOFA, the data matrix is standardized (for each location, the mean is removed from the time series and the remaining anomalies then scaled by dividing by their standard deviation) and then decomposed into mutually uncorrelated (orthogonal) modes which have a spatial pattern (these are called the eigenvectors or empirical orthogonal functions) and a temporal amplitude (these are called the eigenfunctions or principal components). The first mode extracted using the EOFA technique explains the largest fraction of variability in the data set, and each subsequent mode explains the largest fraction of the remaining variability. By extracting the first mode, we obtain the time series of SPG-I based on the MSLA data. The sign of an EOF (empirical orthogonal function)/PC is not determined explicitly during the calculation process and may vary between machines and software versions. We therefore define the sign of the EOF and PC in 1993 to be positive and make adjustments as required.

The addition of data points either in space or time also changes the EOF/PC results, which is briefly explored here
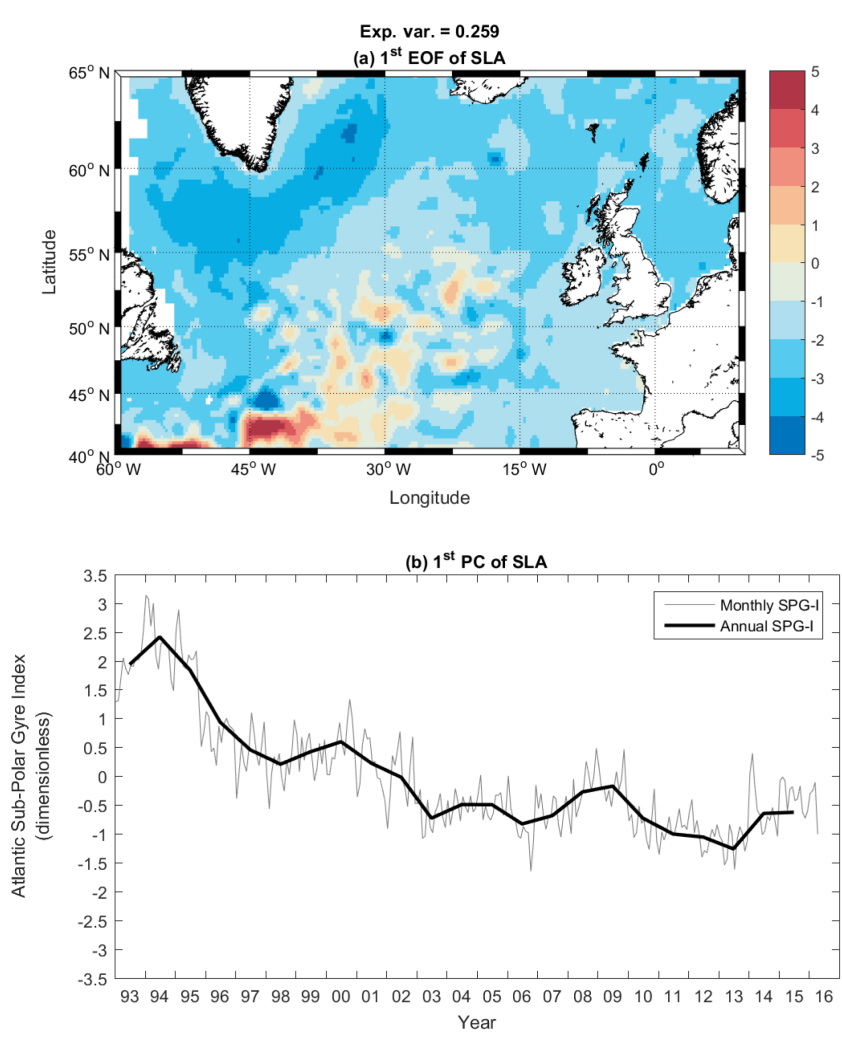

Figure 2. First mode of the EOFA of sea surface height: (a) empirical orthogonal function (spatial field, in centimetres); (b) principal component (temporal variability, dimensionless).

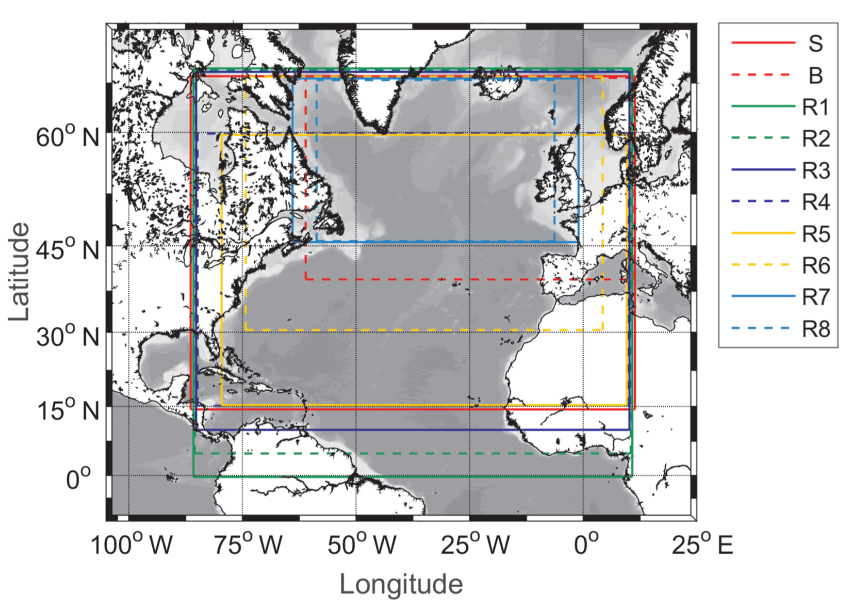

Figure 3. Map of defined regions to investigate sensitivity of SPG-I to the chosen spatial coverage. Details of boundaries are in Table 1. S: S. Häkkinen time series; B: time series presented here; R: time series based on different regions; 1X1: time series presented here based on a $1^{\circ}$ by $1^{\circ}$ grid; $2 \mathrm{X} 2$ grid: time series presented here based on a $2^{\circ}$ by $2^{\circ}$; all other time series presented here are based on a $1 / 4^{\circ}$ by $1 / 4^{\circ}$ grid. 

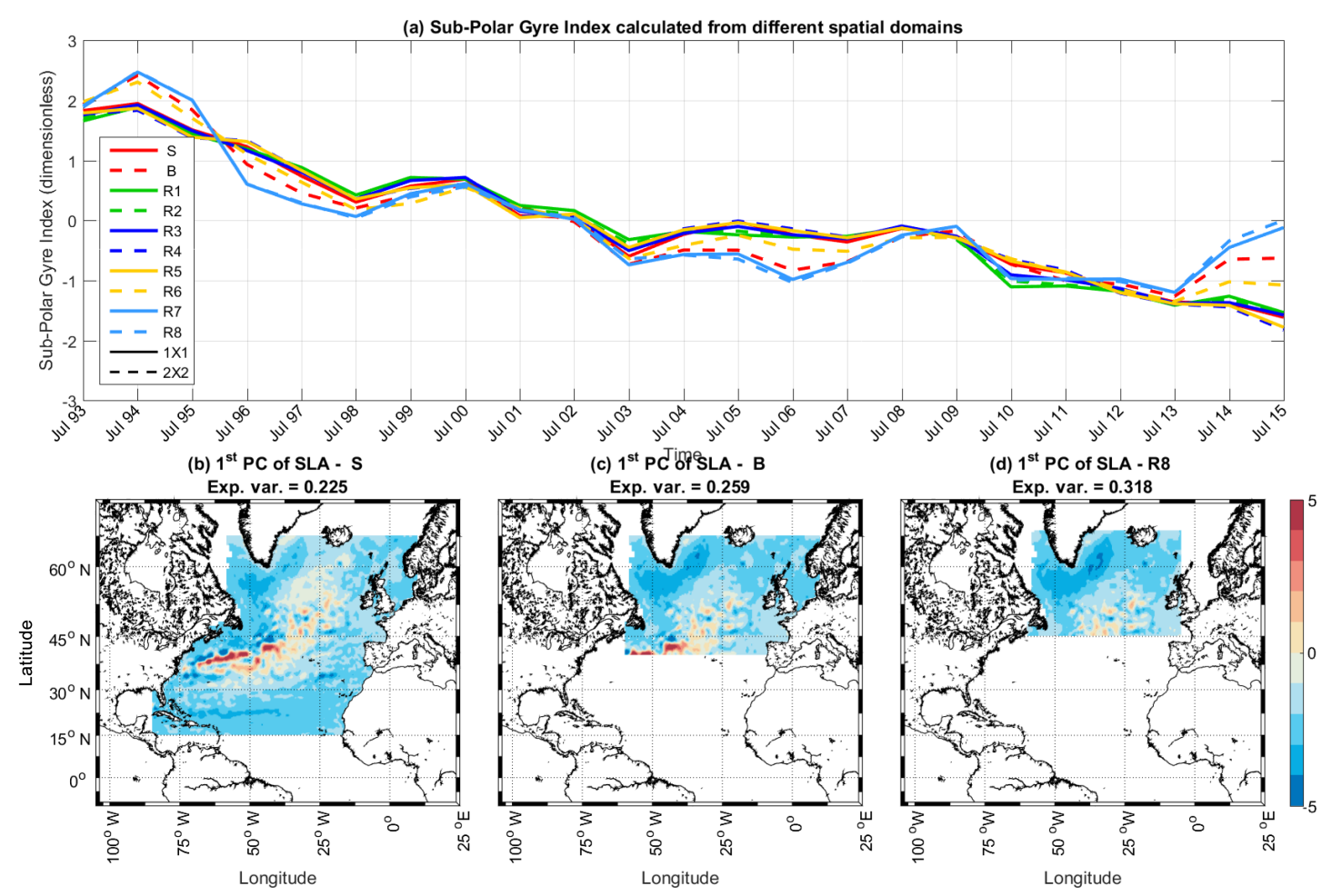

Figure 4. Comparison of yearly SPG-I for different domains within the North Atlantic: (a) yearly SPG-I time series; (b-d) corresponding empirical orthogonal function (spatial field, in centimetres) for three domains. Table 1 and Fig. 3 show the defined areas used in the EOFA. Colours in (a) correspond to those used in Fig. 3.

(Sect. 3). For the user, this means the entire time series needs to be updated when the temporal coverage of the data is updated. To investigate the impact of the chosen spatial extent of data included in the EOFA, we performed the analysis on a number of different regions centred on the sub-polar North Atlantic. These results were based on the $1 / 4^{\circ}$ by $1 / 4^{\circ}$ grid, although time series based on the $1^{\circ}$ by $1^{\circ}$ grid and $2^{\circ}$ by $2^{\circ}$ grids are also presented. The longitude and latitude limits of these regions are listed in Table 1 and shown in Fig. 3.

\section{SPG-I time series}

\subsection{Interpretation}

Figure 2 shows the first principal component (i.e. temporal variability) of the SPG-I and corresponding empirical orthogonal function (i.e. the spatial field). The spatial field shows the signature of the Gulf Stream-North Atlantic Current variability (eddy-like features in Fig. 2a) as well as the lower sea level in the sub-polar gyre region compared to the sub-tropical Atlantic. This first mode of the EOFA explains $25.9 \%$ of the total variance. The second and third mode explain 8.6 and $6.4 \%$ of the variance, respectively. Their interpretation is less studied, and as they are unrelated to published work on the sub-polar North Atlantic, they are not discussed further here.
In the SPG-I time series (Fig. 2b), positive values of the index are associated with a strong sub-polar gyre circulation with a wide spread. In comparison, negative values of SPG-I are associated with a weak sub-polar gyre and westward retraction. The commonly reported weakening and contraction of the sub-polar gyre can be seen in the mid to late 90s (Hátún et al., 2005; Häkkinen and Rhines, 2004). More recently the sub-polar gyre has been variable but remains weak (Fig. 2b).

The exact mechanism whereby changes in the sub-polar gyre state influence circulation across the North Atlantic basin continues to be an area of active research. Hátún et al. (2009b) present a schematic representation of how a weaker sub-polar gyre allows for greater advection of sub-tropical water masses (see their Fig. 2). The changes in the subpolar gyre have recently been proposed to be a response to a prolonged positive NAO phase (Lohmann et al., 2009; Häkkinen et al., 2011; Robson et al., 2012). The atmospheric forcing and storm track variability strengthen the Atlantic Meridional Overturning Circulation, enhancing the northward transport of heat in the oceans and subsequent negative feedback on the sub-polar gyre circulation. Both Lohmann et al. (2009) and Robson et al. (2012) highlight the importance of the ocean's heat transport in the dynamics of the sub-polar gyre. 

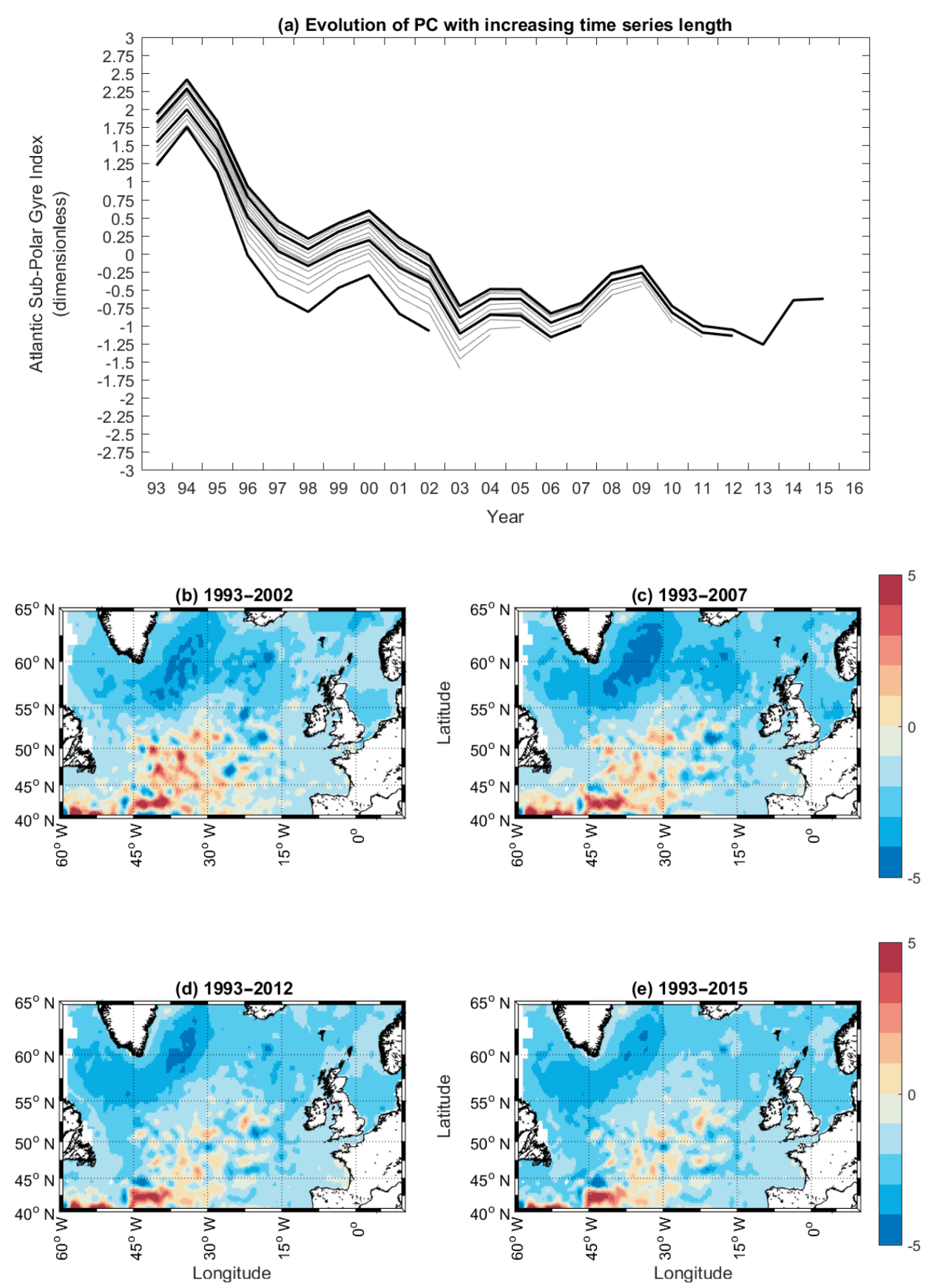

Figure 5. Sensitivity of yearly SPG-I to time series length: (a) principal component (temporal variability, dimensionless) for time periods from 1993 to 2002, increasing 1 year in length (grey lines) with periods shown in (b-d) in bold black lines; empirical orthogonal function (spatial field, in centimetres) for four time periods: (b) 1993 to 2002, (c) 1993 to 2007, (d) 1993 to 2012, and (e) 1993 to 2015.

\subsection{Sensitivity to spatial extent}

To investigate the sensitivity of the SPG-I to the chosen spatial domain for the EOFA, the analysis was repeated for a number of different regions (Fig. 3 and Table 1). The results for the annual SPG-I, shown in Fig. 4a, show that a separation does occur between indices focused solely on the subpolar region (time series B, R6, R7, and R8 in Fig. 4a) and those incorporating a wider region of the North Atlantic. In particular, when including the region in the tropical North Atlantic Ocean, the SPG-I becomes strongly linear. The correlations between time series based on these various regions are high (all greater or equal to $0.90, p<0.001$ ). The correlation coefficients also highlight that indices calculated from regions restricted to the sub-polar North Atlantic correlate well to each other but less well to those calculated over the 


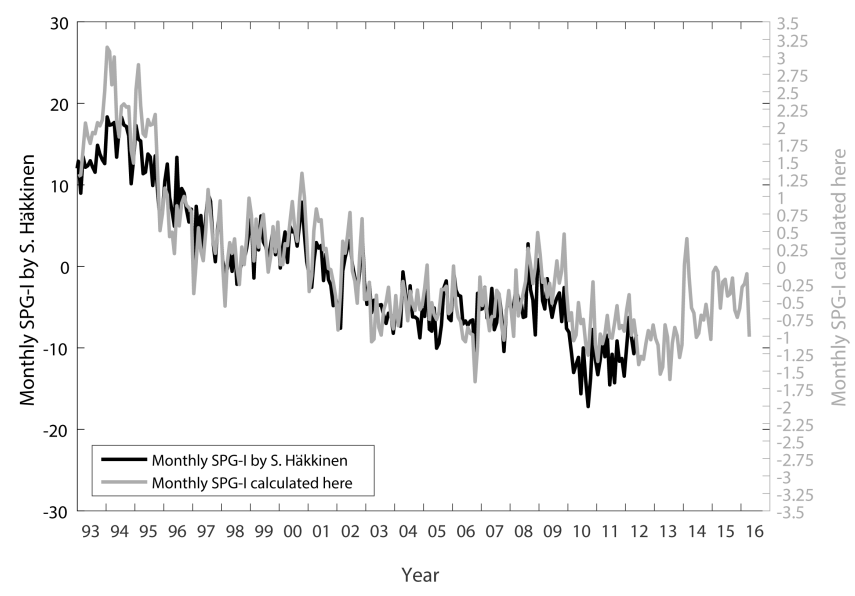

Figure 6. Comparison of SPG-I calculated here with that calculated by $\mathrm{S}$. Häkkinen, based on monthly time series

wider North Atlantic, with $r$ values dropping from 0.99 to approx. 0.92. Linear detrending of the index time series prior to the correlation analysis does not influence this outcome: the lower correlation coefficients are between $0.53-0.98$, but all remain statistically significant and exhibit the same pattern. This pattern is due to the fact that the SPG-I calculated for regions narrowly confined to the sub-polar North Atlantic has a higher level of inter-annual variability.

\subsection{Sensitivity to time series length}

To highlight the impact of increasing time series length on the SPG-I, the analysis was performed on the first 10 years of altimeter data (1993 to 2012), increasing time series length by time increments of 1 year (Fig. 5). The analysis highlights to the user the need to access the latest SPG-I time series: although the overall pattern of the SPG-I in preceding years remains unchanged, there are minor changes in the values of the time series. When updating the index, users should always download the entire SPG-I time series. The consistency of the index time series with increasing time series length, as seen in Fig. 5, confirms that the SPG-I can be defined robustly as the first PC of an EOFA of SLA (sea level anomaly) and that the statistical mode of the analysis has a dynamical meaning.

\subsection{Comparison to previous results}

The SPG-I presented here has been compared to similar indices previously presented by S. Häkkinen (Häkkinen and Rhines, 2004, 2009) and H. Hátún (Hátún et al., 2009a, b). A first comparison (Fig. 6) shows the comparison of the monthly resolution SPG-I time series to that previously presented by S. Häkkinen (S. Häkkinen, personal communication, 2013). These two time series show close agreement, and minor differences are likely due to different underlying altimeter data products and the change in time series extent.

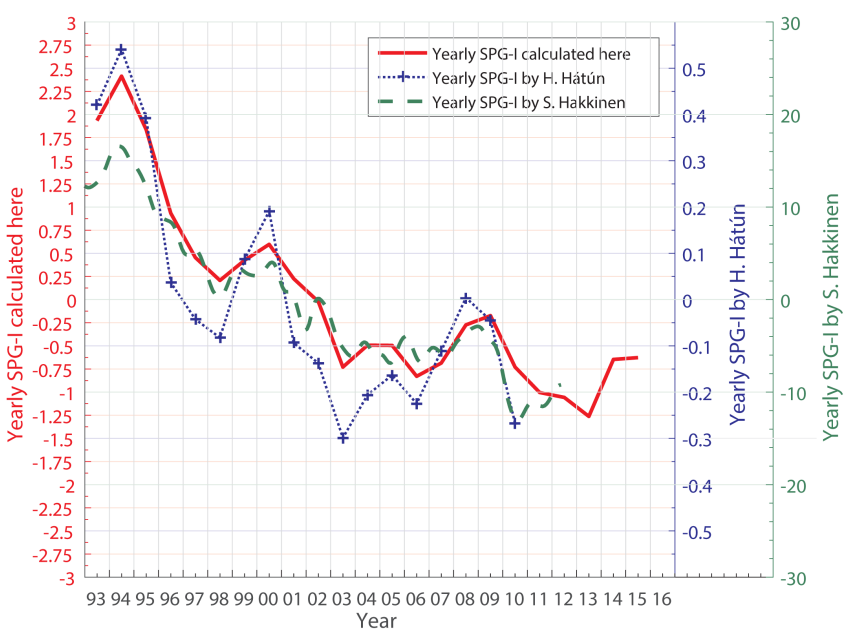

Figure 7. Comparison of yearly SPG-I with that calculated independently by S. Häkkinen and H. Hátún. See text for more details.

There is also a difference in scaling between these two indices by 2 orders of magnitude, most likely due to differing units (centimetres vs. metres). However, as the typical usage of the data set is in terms of its correlations with other variables, rather than interpreting its absolute value, this discrepancy is not seen as important. In a second comparison (Fig. 7), the annual filtered time series by S. Häkkinen has been compared to the annual SPG-I calculated here and the time series estimated by H. Hátún based on annual mean SSH (sea surface height) data (H. Hátún, personal communication, 2012). Again, the overall pattern of these three indices shows good agreement, with all showing a clear reduction in the SPG-I in the mid to late nineties. The difference between this third index time series in comparison to the previous two is due to a different underlying altimeter product $\left(\mathrm{a} 1 / 3^{\circ}\right.$ by $1 / 3^{\circ}$ Mercator grid, which placed additional emphasis on the sub-polar gyre region).

\section{Data availability}

Following the recommendations of Berx et al. (2011), we would like to ensure the SPG-I time series presented here is easily accessible and available to all. The data can therefore be downloaded from http://dx.doi.org/10.7489/1806-1 in ASCII format, and researchers can also access the supporting information there (including code to recreate the index). We are committed to updating the time series within 6 months from the time the data provider (CMEMS) publishes its updates. As the time series is based on the EOFA technique, we recommend users download the entire index time series when updating the time series they use. This will ensure the most relevant time series is used in any analyses. Version numbering will facilitate users identifying which version of the time series they are accessing. Finally, we would appreciate it if all those making use of this time se- 
ries appropriately acknowledged its use by citing this paper and the digital object identifier (DOI) of the data set.

\section{Summary}

We have presented a time series of SPG-I based on monthly mean SLA maps obtained from CMEMS. Our time series compares well with indices presented previously. The variability in the index time series is influenced by the chosen spatial extent of the sea surface height data included in the EOFA, and inter-annual variability is suppressed when including the wider North Atlantic region. We also presented an indication of changes with temporal coverage of the data series, and users need to ensure downloading the entire time series when accessing future updates. The index data product we present is freely available from http://dx.doi.org/10.7489/ 1806-1, and we encourage all scientists interested in establishing linkages between North Atlantic climate variability and ecosystem function to access, apply, and publish.

Competing interests. The authors declare that they have no conflict of interest.

Acknowledgements. We would like to thank Sirpa Häkkinen and Hjalmar Hátún for providing their time series of SPG-I and ancillary information relating to their calculation; we are grateful to Hjalmar Hátún and Stuart Cunningham for useful discussions on sub-polar gyre dynamics. The research leading to these results has received funding from the European Union 7th Framework Programme (FP7 2007-2013) under grant agreement number 308299 (NACLIM).

Edited by: G. M. R. Manzella

Reviewed by: three anonymous referees

\section{References}

Bersch, M., Yashayaev, I., and Koltermann, K. P.: Recent changes of the thermohaline circulation in the subpolar North Atlantic, Ocean Dynam., 57, 223-235, 2007.

Berx, B., Dickey-Collas, M., Skogen, M. D., De Roeck, Y.-H., Klein, H., Barciela, R., Forster, R., Dombrowsky, E., Huret, M., Payne, M., Sagarminaga, Y., and Schrum, C.: Does operational oceanography address the needs of fisheries and applied environmental scientists?, Oceanography, 24, 166-171, doi:10.5670/oceanog.2011.14, 2011.

Bessières, L., Rio, M. H., Dufau, C., Boone, C., and Pujol, M. I.: Ocean state indicators from MyOcean altimeter products, Ocean Sci., 9, 545-560, doi:10.5194/os-9-545-2013, 2013.

Emery, W. and Thomson, R.: Data Analysis Methods in Physical Oceanography, Elsevier, 2nd Edn., 2001.

Häkkinen, S. and Rhines, P. B.: Decline of Subpolar North Atlantic Circulation During the 1990s, Science, 304, 555-559, doi:10.1126/science.1094917, 2004.
Häkkinen, S. and Rhines, P. B.: Shifting surface currents in the northern North Atlantic Ocean, J. Geophys. Res., 114, C04005, doi:10.1029/2008JC004883, 2009.

Häkkinen, S., Rhines, P. B., and Worthen, D. L.: Atmospheric Blocking and Atlantic Multidecadal Ocean Variability, Science, 334, 655-659, doi:10.1126/science.1205683, 2011.

Hátún, H., Sandø, A., Drange, H., Hansen, B., and Valdimarsson, H.: Influence of the Atlantic subpolar gyre on the thermohaline circulation, Science, 309, 1841-1844, 2005.

Hátún, H., Payne, M., and Jacobsen, J. A.: The North Atlantic subpolar gyre regulates the spawning distribution of blue whiting (Micromesistius poutassou Risso), Can. J. Fish. Aquat. Sci., 66, 759-770, 2009a.

Hátún, H., Payne, M. R., Beaugrand, G., Reid, P. C., Sand $\varnothing$, A. B., Drange, H., Hansen, B., Jacobsen, J. A., and Bloch, D.: Large bio-geographical shifts in the north-eastern Atlantic Ocean: From the subpolar gyre, via plankton, to blue whiting and pilot whales, Prog. Oceanogr., 80, 149-162, doi:10.1016/j.pocean.2009.03.001, 2009b.

Hátún, H., Lohmann, K., Matei, D., Jungclaus, J., Pacariz, S., Bersch, M., Gislason, A., Ølafsson, J., and Reid, P.: An inflated subpolar gyre blows life toward the northeastern Atlantic, Prog. Oceanogr., 147, 49-66, doi:10.1016/j.pocean.2016.07.009, 2016.

Holliday, N. P., Hughes, S., Bacon, S., Beszczynska-Möller, A., Hansen, B., Lavín, A., Loeng, H., Mork, K., Østerhus, S., Sherwin, T., and Walczowski, W.: Reversal of the 1960s to 1990s freshening trend in the northeast North Atlantic and Nordic Seas, Geophys. Res. Lett., 35, L03614, doi:10.1029/2007GL032675, 2008.

Hurrell, J. and National Center for Atmospheric Research Staff: The Climate Data Guide: Hurrell North Atlantic Oscillation (NAO) Index (PC-based)., Tech. rep., last modified: 10 May 2013, available at: https://climatedataguide.ucar.edu/climate-data/ hurrell-north-atlantic-oscillation-nao-index-pc-based (last access: 5 February 2016), 2013.

ICES: Report of the Working Group on Operational Oceanographic products for Fisheries and Environment (WGOOFE), 12-16 March 2012 and 6-8 November 2012, ICES HQ, Copenhagen and Brussels, Belgium., Tech. Rep. ICES CM 2012/SSGSUE:06, 2012a.

ICES: Report of the Working Group on Widely Distributed Stocks (WGWIDE), 21-27 August 2012, Lowestoft, United Kingdom, Tech. Rep. ICES CM 2012/ACOM:15, 2012b.

Johnson, C., Inall, M., and Häkkinen, S.: Declining nutrient concentrations in the northeast Atlantic as a result of a weakening Subpolar Gyre, Deep Sea Res. Pt. I, 82, 95-107, doi:10.1016/j.dsr.2013.08.007, 2013.

Lohmann, K., Drange, H., and Bentsen, M.: A possible mechanism for the strong weakening of the North Atlantic subpolar gyre in the mid-1990s, Geophys. Res. Lett., 36, 115602, doi:10.1029/2009GL039166, 2009.

National Geophysical Data Center, N. o. C.: TerrainBase, Global 5 Arc-minute Ocean Depth and Land Elevation from the US National Geophysical Data Center (NGDC), 1995.

Overpeck, J. T., Meehl, G. A., Bony, S., and Easterling, D. R.: Climate Data Challenges in the 21st Century, Science, 331, 700702, doi:10.1126/science.1197869, 2011. 
Payne, M. R., Egan, A., Fässler, S. M., Hátún, H., Holst, J. C., Jacobsen, J. A., Slotte, A., and Loeng, H.: The rise and fall of the NE Atlantic blue whiting (Micromesistius poutassou), Mar. Biol. Res., 8, 475-487, 2012.

Robson, J., Sutton, R., Lohmann, K., Smith, D., and Palmer, M. D.: Causes of the Rapid Warming of the North Atlantic Ocean in the Mid-1990s, J. Climate, 25, 4116-4134, doi:10.1175/JCLI-D-1100443.1, 2012.
Schneider, D. P., Deser, C., Fasullo, J., and Trenberth, K. E.: Climate Data Guide Spurs Discovery and Understanding, Eos, Transactions American Geophysical Union, 94, 121-122, doi:10.1002/2013EO130001, 2013. 